\title{
The Name of the Game is Mathematics: How Do Mathematics Teachers of Primary Schools Motivate Learners?
}

\author{
Maimane Joseph Ramathibela
}

Central university Of Technology Email:jrmaimane@cut.ac.za

Rankhumise Mmushetji

Petrus Central university Of Technology RSA

Email:mprankhumise@cut.ac.za

\section{Doi:10.5901/mjss.2014.v5n15p434}

\begin{abstract}
Understanding concepts and rules in mathematics is fun and once learners are in command of them, mathematics turns into a simple and easy game to play. The performance of the learners seems to increase with every game they play. Once learners have grasped the concepts and rules, teachers seem not to experience major problems in presenting the new subject matter to them. The paper tries to explore the way primary school mathematics teachers in Mangaung township (Republic of South Africa) motivate their learners in solving and understanding mathematical concepts and instructions as experienced in the classroom. Observation of lesson presentation used in the gathering of data and textually oriented discourse analysis is the method used for data analysis. The results indicate that approaching mathematics as a game to be played enhances the interests of the learners. Their work rate and ownership of the subject increases. Mother-tongue plays a significant role in the understanding of mathematical concepts.
\end{abstract}

\section{Introduction}

This paper was conceived after reading the research done by Setati(1999) and Koen (2000). The emphasis is on the work done by the latter. The view that emanates from Koen's paper, calls for the response that more than the physical and cognitive aspect of the learner, structure of the content and the context in which learning takes place, has an impact on how learners come to view the subjects they do.

The area of study is Mathematics in Grade 5 (Intermediate Phase i.e. Grade 4- 6) in the Mangaung township. The Intermediate phase is one of the four phases (preschool; foundation phase; senior phase) of the general education and training band, which forms part of the eight qualification levels of the National Qualification Framework (NQF) as developed by the South African Qualification Authority (SAQA). In this phase learners are capable of understanding relationships between materials, incidents, circumstances and people, and are able to deduce the consequences of such relationship (Lemmer \& Badenhorst, 1997). Mangaung township is one of the poorest Black townships (a township can be compared to an American ghetto/a housing project or a housing estate as in UK in South Africa with inadequate learning facilities as compared to those of white schools, which benefited from the previous government.

The paper tries to argue that motivation plays an important role in the enjoyment of mathematics as a game. Teachers are the main role players in motivating learners to understand the rules of the game and that mother-tongue mediates in the understanding of mathematical concepts. Using first language in foreign language classes can be a communication strategy that helps learners to compensate for their deficiency in the second language (Rahimi, \& Kiyoumarsi, 2010)

\section{Theoretical Framework}

Vygotsky's zone of proximal development (ZPD) stands out as the main theoretical point of departure for this study. The underlying assumptions behind the concept are that psychological development and instruction are socially ingrained. To understand these assumptions one need to analyse the surrounding community and its social relations. To be able to understand them a form of guidance is crucial because there are multitude of things that a person encounters during a 
process of development. To be mentally, emotionally, spiritually, aesthetically and socially developed the direction of development is guided by instruction in scientific concepts considered to be important by the curriculum planners and teachers. Vygotsky points out that the main characteristics of instruction are that it creates the zone of proximal development, stimulating a chain of inner developmental processes. Daniels (1996) quotes Vygotsky as stating that: The child is able to copy series of actions which surpass his or her own capacities, but only within limits. By means of copying, the child is able to perform much better when together with and guided by adults than when left alone, and can do so with understanding and independently. The difference between the level of solved tasks that can be performed with adult guidance and help and the level of independently solved tasks is the zone of proximal development.

Sierpinka \& Lerman (1996) argue that the zone of proximal development has to do with the difference between what she/he could do on her/his own and what she/he could do with the help of a more experienced person. The idea behind the theory is that learning takes place with others and that it attracts other person to be a participant so that what she/he sees others doing today, she/he will do with them tomorrow and alone thereafter. What it means is that education is a collective activity which calls for a skilled person to guide the inexperienced individual by applying mediation tools (physical objects as well as symbolic) available to them at that point in time. The teacher is an experienced person who mediates between the learners and the subject matter because of her content knowledge by code-switching, that is by moving from English into Setswana so that learners could understand, concepts, strategies and rules embedded in the game, fractions manipulation in mathematics.

Another theory that gives substance to this study is Sfard's theory of reification. At the core of

this theory is the idea that different mathematical notions can be thought of in two fundamentally different ways, namely, structurally (as objects) and operationally (as processes). Highlighting these two approaches, she does not consider them as separate entities but as being complementary. She is of the opinion that successful learning and problem-solving require the ability to move from one domain to the other (Sfard, 1991). According to Bowie (2000), reification is the most difficult process compared to interiorisation, (has to do with becoming familiar of a process and being able to carry it out through mental representations, and condensation, that is a gradual quantitative change in which a sequence of mathematical operations is dealt with), as it involves a quantitative shift in understanding. This shift occurs when the learner is able to break the impressions from the process that produced it and see it as an object. Fraction manipulation might be regarded as activities that the learners can literally deal with as objects or can be viewed by the learners as a means of grasping and communicating mathematically with others or with themselves as individuals. As an experience person, the maths teacher has the capacity and knowledge of intervening in the mathematical activities of learners. In other words, reification has to do with the moment when learners see functions as objects that they are able to perform on their own.

Other area that informs this paper is the work of Leicha (2007) and Koen (2000) which describes mathematics as being a fascinating game which learners can enjoy provided they are affectively motivated. She maintains that intrinsic motivation does not come naturally and that a teacher needs to handle the teaching and learning situation in a very special way to generate intrinsic motivation.

One other area that has an influence on the paper is that of Ditshego (1999) where he uses cards to show that mathematic can be handled as a game. In this game, teamwork is emphasised and the winning team is the one that comes first if it is able to go through twenty-four mathematical manipulations.

Setati (1998) has an impact on this paper because of her vast research work based on mathematics teaching in disadvantaged black schools in South Africa. In her studies she points out that code-switching has an enormous impact in being able to interact mathematically with others. She points out that if the language of the learner is not used in mathematical discourse, maths will remain formal and procedural.

Bilingual speakers are known for their ability to effectively code switch or mix their languages during communication. Code switching occurs when bilinguals substitute a word or a phrase in one language with a phrase or word in a second language (Heredia \& Altarriba, 2001). According to (Skiba, 1997) code switching among bilinguals in a normal conversation consists of eighty four percent (84\%)single word switches, ten percent (10\%) phrase switches and six percent (6\%) clause switching.

Myers-Scotton (1993:1) one of the authorities on code switching, defines it as the alternation of two or more languages within the same conversation. She makes a distinction between code switching and code mixing, and asserts that code switching occurs when bilinguals alternate between two languages during an interaction with another bilingual person. Instances of code mixing occur in the speech of the people who are not proficient in one of the two languages. For example, code switching between English and Setswana among Black South African students and teachers, where the students and the teachers are not proficient in English which is not their mother tongue, for the reason that they learnt English and acquired Setswana. Code mixing involves the use of affixes, words, phrases and clauses from more than 
one language within the same sentences and speech situation. She concludes that both code switching and code mixing occur within the same discourse.

Romaine (1989: 186) makes a distinction between code switching and code mixing by saying that code switching occurs where a certain level of language competence is needed and code mixing occurs in the early stages of language acquisition. She attributes code mixing to language interference and transference.Skiba (1997) asserts that code switching is not language interference based on the fact that it supplements speech. Unlike Romaine (1989) and MyersScotton (1993), Lehiste (in Mncwango, 2004) defines code switching as the alternation of two languages by the same speaker during the same speech event. However, he does not distinguish between mixing and switching and does not mention anything about the level of proficiency of the person. Mati (2004) points out that the ability to code switch is an important tool for the individual in the learning process within the context of a multilingual andmulticultura1 society. This author stressed further by citing Adendorff (1993) that 'switches are viewed as guiding the participant's interpretation of academic goals and intentions as well as guiding their interpretation of social relationships in the class and he advocates that teachers be given instruction in the value of code switching in their training.

Historically, code switching has been seen as having inferior status. Many people regard it as a grammarless mixture of languages and equally believe that people who code-switch are not proficient to converse in either of the two languages (Setati, 2002). Moyo (2000) argues that most bilinguals are fairly capable of maintaining proficiency in their respective first languages. Moreover, some people hold the view that it lowers communication standards and students who do not share the same first language will be neglected (Cook, 2002 cited in Sert, 2005). The competence level of the teacher in the first language is also taken into consideration (Sert, 2005). The literature increasingly reflects the view that code switching in classrooms is normal, useful and provides continuity in speech when effectively used, as transference of meaning to weak learners. It helps the students and teachers with both communication and social interaction (Ncoko Osman,, and Cockcroff, 2000; Rose \& Dulm, 2006; Skiba, 1997; Setati, 2002).

\section{Justification of the Study}

This study is important because it demonstrates that personal touch or mutual co-operation is vital in the understanding of issues related to teaching mathematics effectively. What this means is that research is able to highlight the plight of those who are being researched like in the case of this study in which the teacher is faced by a large class.

The study is conducted in a bid to contribute to the growing volumes of literature which argues

that even the poorest of the poor South African people have a place in the sun and as such, they cannot be ignored and be relegated to the margins and outer boundary of education and economical needs.

This study tries to indicate that not one approach is sufficient in teaching mathematics but rather an integrated approach should be used because learners are unique and that motivation is very important in mastering mathematics.

This study is also important because it interrogates the type of communication used in the classroom during maths teaching. It tries to shed light on the role mother-tongue plays in the understanding of some rule and concepts which the learner should know and own.

The study is also important because it alerts learners, parents, educationists and the whole country that teachers as mediators in teaching and learning are important in motivating learners to understand the rules of the game, mathematics. Koen (2000) avers that learning is greatly enhanced when the learner is affectively motivated.

This study is also important because it makes future researchers to be mindful of environmental and social dynamics that impacts on the overall development of the researched and that they should try to be sensitive to the researched socio-economic conditions. Cosin, Dale, Esland, Mackinnon and Swift (1977) maintain that the cultural processes of the classroom represent the combined actions of pupils and teachers subcultures in a setting already largely determined by social processes operating outside the classroom and the school.

\section{Methodology and Research Design}

This study is qualitative in nature (Cohen \& Manion 1994; Uys \& Basson 1991) as the focus is on Grade 5 classes which were randomly chosen from the other grade 5 classes. The study is also descriptive and exploratory (Bailey 1982; Uys \& Basson 1991) in the sense that it tries to describe in detail the activities that the teachers and the learners do. The study is also exploratory because it tries to elucidate the motivation that is consciously or unconsciously used by the teachers during mathematics lessons in order that learners should be able to follow the rules of the game.

To analyse the observed lessons, Fairclough's (1992) textually oriented discourse analysis (TODA) was used. The reason for using this method is that it is not about positivism=s quantification, external validity, objectification, prediction, 
formulation of universal laws, nor establishment of causal relations (Mahlomaholo, 1998). The strategy concentrates on what people say and describes that as evidence to authenticate the interpretations.

\subsection{Procedure And The Context}

Permission to gather information from the school was granted by the principal of Unity Primary school. Unity Primary school is a makeshift corrugated iron school within a school with a population of approximately one thousand learners. In my discussions with the principal, she told me that there were five Grade 5 classes in here school. From this information two classes were randomly selected for the purpose of collecting information. Observation of mathematics lessons was conducted after discussing my intentions with the teachers and learners whose classes were selected. During observation notes were taken and a tape-recorder was used in order to capture some of the comments during instructions. At the end of the week that is on Friday the last two lessons of the series of the topics on fractions were video-recorded.

Learners in class A are of mixed age group that is, varying from 11-14 years age. The class is composed of 31 girls and 20 boys. All the learners have been doing mathematics as part of the curriculum. Motshidisi, the teacher, is a married lady and her qualification is university diploma in education, secondary (UDES). She has seven years experience in teaching mathematics- four years in the secondary school and three years in the primary school, that is intermediate phase. She is a Setswana speaking person and less than 40 years old. She communicates easily with her learners in Setswana and she is able to speak two other African languages. James on the other hand is less than two years in teaching and has senior education diploma (SED). He is also Setswana speaking person. His class, that is class B, has 25 boys and 33 girls. Like learners of the former class, his learners can communicate in Setswana and English. The medium of instruction used in teaching mathematics is English. While their mastery of English cannot be compared to a first language speaker, they are able to communicate in it.

\subsection{How The Game Is Played}

Various mathematical activities were conducted during the course of the study, that is, a week. As stated above, the lessons were recorded. It is therefore important to show how the game of fractions is played. This is how it went:

In the initial phase of the lesson the teacher asked the learners questions about the previous work done. Thereafter she wrote the topic fractions on the chalkboard. This is lesson 1 of the recorded work. She then requested them to have a clean sheet of paper and she said:

Teacher: Fold it nicely. It must be equal. (E lekane, meaning it must be equal).

What comes in your head? (Oh! come on.).

What is a fraction? (Ao!, le lebetse? Meaning "have you forgotten"? , Itekeng meaning "try it")

What comes in your head?

At this time learners seem to be unsettled which could be attributed to the fact that a stranger, that is, the researcher, was in their classroom. Seeing this, the teacher used Setswana to calm them down and she repeated the question in their mother-tongue and changed the strategy of getting the answer still using English.

Teacher: Can any one of you goes and write a fraction on the board? [At this point most of the learners ran to the board and she called them back, letting one girl to write.]

What fraction has she written on the board?

Answer: One third [this is in chorus]

Teacher: Good. (Le tota le le bothale meaning "you are really clever").

The teacher then explains that a fraction will always have a number on top of a line and one below and she explains that the denominator is the one above the line while the numerator is the one below. The explanation is done by writing the fractions on the board accompanied by pointing them out. She then expresses some appreciation and motivation. At the end of the game of fractions she said:

Teacher: Boys won the first activity. They had one point. The second activity is won by girls. So, we have a draw.

The game ends with learners being overjoyed that the game was a draw. Thereafter the teacher gave them 
homework to do and she dismissed them.

Lesson two, follow the same pattern as that of Lesson one. The only difference is that colours are used in teaching fraction.

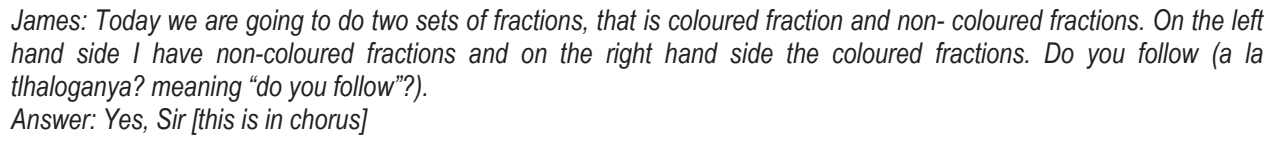

James: Today we are going to do two sets of fractions, that is coloured fraction and non- coloured fractions. On the left hand side I have non-coloured fractions and on the right hand side the coloured fractions. Do you follow la la thaloganya? meaning "do you follow"?).

Answer: Yes, Sir [this is in chorus]

James: On the table in front of you there are little paper designs of fractions. So I want you to give them names according to the way they are coloured. I want you to say the fraction with its colour. (Dirang ka pele meaning be fast, Basimane ba kae? meaning "where are the boys"?

The teacher wrote the different fractions on the board and instructed learners who never wrote on the chalkboard to have a chance and it should be a boy and a girl. The game continued like that until all the fractions were covered. His concluding words before closure were:

James: So, in this case nobody won. So, the score is one each. It is a draw.

Learners were then reminded to write homework down before leaving for play-time.

\subsection{Observations And Findings}

What the study shows is that although the classroom is overcrowded, the teachers are able to bring order by grouping the learners. They even call them by their names and sometimes invoke panic by saying that those who are caught making noise will remain behind during play-time.

Although learners participate as groups with leaders, the teachers seem to be the pivot because they are the ones who direct and intervene whenever one group goes astray yet they do not give the members of the group enough chance to take care of the situation on their own initiative.

The way the lessons are being conducted learners enjoy themselves because the teachers motivate them by inculcating the spirit of competition in every activity they undertake. Colour is also used to help learners to recognise concepts on the chalkboard when asked to locate them.

The teachers use the integrated approach to impart the learning content. They can move from the child-centred approach to the cognitive approach when need arises. To attract and to motivate the learners, they incorporate various mediating tools available in the classroom. The discourse used in all the lessons was characterised by every-day language which kept the lesson flowing, enjoyable and accessible.

\section{Discussion}

The paper indicates that intervention by a teacher is important in a mathematics classroom so that learners could follow what is being taught or when clarity on concepts is sought. This is shown by Motshidisi when she was looking for clarity from the learners: (I don't see sixteen portions here. Try to concentrate and get the right answer. This motivation is advocated by Vygotsky's zone of proximal development theory which stresses the interaction of a child with adults and how instructional interventions can enhance the development of the child (Sierpinska 1994). In the presence of a teacher, learners are able to construct and explain some rules regarding fractions with the given guidance (Mudaly \& de Villiers 2000).

The type of mediation tools (language, gestures, charts and objects in the classroom) used during the lesson presentations helped the learners to play the game. The teachers in this study are able to switch from Setswana to English or from the former to the latter in order to express or clarify fractional concepts: (Fa o di tshwaya kafa le kafa o tla araba dipotsao jang? meaning "If you mark them on both side how you will give the answer". Setati (1998) indicates that code-switching is necessary in mathematics because without it mathematical discourses would remain formal and procedural. Sierpinska (1994) points out that the language of the teacher is not only based on mathematical symbols. As far as she is concerned, it is more of the every day spoken language which is constituted of didactical jargon and mathematical terms and that each of these languages have its own conventions which might not be compatible with each other. 
The problems encountered in the lesson presentations were solved by the ability of the teachers to be able to move from one domain to another. When James noticed that learners were not able to identify the fractions on the chart, he wrote them on the board. This is in agreement with Sfard's notion of reification which maintains that successful learning and problem-solving require the ability to move from one domain to another (Sfards1991).

When a learner concentrated on activities outside the lesson, the teacher would redirect that learner by posing a question and asking that learner to respond to it. This is evident when James said to one girl: ( Mosetsana bowa kwa 0 leng teng meaning girl,meaning "come back from where you are". This redirection of the learner indicates that the quality of the lesson depends on mutual co-operation.

During a discussion with Motshidisi, she indicated that their learners seem not to know what they have been taught the previous day and she blames this on parents and explosion in knowledge due to technology which is inaccessible to parents and learners. In other words, processes outside the school environment determine, on a larger scale, the interaction of the teacher and the pupils in the classroom. Cosin, Dale, Esland, Mackinnon and Swift, (1977) maintain that the cultural processes of the classroom represent the combined actions of pupils and teachers subcultures in a setting already largely determined by social processes operating outside the classroom and the school.

In conclusion, I am tempted to say that successful teaching of mathematics in disadvantaged societies is a challenging task that needs patience, dedication and empathy. The ability of the teacher to deal with mixed groups of children in mathematics is a taunting task because of the uniqueness of these souls. The above primary maths teachers seem to be conversant with their subject. They made use of the integrated approach and code-switching to motivate the learners to follow the rules of the game and to enjoy it. What is very important is that we should bear in mind that the use of the integrated approach and the mother-tongue of the learners do not ensure complete internalisation and manipulation of mathematical discourses of fractions. The need to further explore these areas in future is necessary and imperative.

\section{References}

Bailey, K. D. 1982. Methods of social research. London: The Free Press.

Bowie, L. (2000). A learning theory approach to students= errors in a calculus course. Pythagoras, 52, pp 2-14.

Cohen, L. and Manion, L. (1994). Research methods. London: Croom Helm.

Cosin, B. R. , Dale, I. R., Esland, G. M., Mackinnon, D. \& Swift, D. F. (Eds). 1977. School and society: a sociological reader. London: Routledge \& Kegan Paul.

Daniels, H. ed., (1996). An introduction to Vygotsky. London and New York: Routledge.

Ditshego, M.M.L. (1999). Maths 24 games. Pythagoras, 50, pp 53-56.

Fairclough, N. (1992). Discourse and social change. Cambridge: Polity Press and Blackwell Publishers.

Heredia, RR. \& Altarriba, J. (2001).Bilingual Language Mixing: why do bilinguals code switch. Current direction in Psychological science, 10 (5): 164-168.

Lemmer, E.M. and Badenhorst, D.C. (1997). Introduction to education for South African teachers. Kenwyn, South Africa: Juta.

Koen, S. (2000). The name of the game is mathematics: proposals for the reform of the teaching of Foundation Phase mathematics in South Africa. Pythagoras, 51, pp 10-16.

Mahlomaholo, M.G. (1998). Signification of African cultural identity, individual African identity and performance in mathematics among some standard nine African pupils in Mangaung High Schools. Unpublished D.Ed-thesis. Bellville, South Africa: University of the Western Cape.

Mati, X. (2004)"Using code switching as a strategy for bilingual education in the classroom." A paper presented at the AEAA 21 st Annual conference, Cape Town, South Africa, 25-28, August, 2004.

Mncwango, E.M.(2004) "The effects of code switching on the learners' acquisition of English as a second language." Unpublished Thesis, University of Zululand.

Moyo, T. (2000).Language use in the neighbourhood of Empangeni and Richards Bay. South African Journal of African Languages, 20 (2): 123-133.

Myers-Scotton, C. (1993).Social motivations for code switching. Evidence from Africa,Oxford: Clarendon Press.

Mudaly, V. and De Villiers, M. (2000). Learners= needs for conviction and explanation within the context of dynamic geometry. Pythagoras, 52, pp 20-23.

Ncoko, S., Osman, R., and Cockcroff, K. (2000). Code Switching among multilingual Learners in primary schools in South African: An exploratory study.

International Journal o/Bilingual Education and Bilingualism, 3 (4): 225-241.

Rahimi, E. F \& Kiyoumarsi, F( 2010 ). The Effect of Code Switching on Learning ESP Contexts in Iranian EFL Learners. The International Journal of Learning, Volume 17, Issue 7, pp.139-150.

Romaine, S. (1989). Bilingualism, Oxford: Basil Blackwell.

Rose, S. and Dulm, O.V. (2006)Functions of code switching in multilingual classrooms. PerLinguam: Journal of language learning, 22 
(2): 1-13.

Sert, O. (2005) The functions of code switching in ELT classrooms. The internet TESL Journal, II (8):. Retrieved August 4,2012, from http://iteslj.org/Articles/Sert-CodeSwitching.html

Setati, M. (2002b). Researching Mathematics education and language in multilingual South Africa The Mathematics Educator, 12 (2):620.

Setati, M. (1996 ). Code-switching and mathematical meaning in a senior primary class of second language learners. M.Ed. research report. Johannesburg, South Africa: University of the Witwatersrand.

Sfard, A. (1991). On the dual nature of mathematical conceptions: reflections on process and object as different sides of the coin. Educational Studies in Mathematics, 22, pp 1-36.

Sierpinska, A. (1994). Understanding in Mathematics. London: The Falmer Press.

Sierpinka, A. and Lerman, S. (1996). Epistemologies of mathematics and Mathematic Education, in: Bishop, A.J., Clements, K., Keite, C. Kilpatrick, J. and Laborde, C. eds., International handbook of Mathematics Education. The Netherlands: Kluwer.

Skiba, R. (1997). Code switching as a countenance of language interference. The internet TESL Journal, 3 (10): Retrieved May 28, 2013,http://iteslj .org/Articles/Skiba-CodeSwitching.html

Uys, H. H. M. \& Basson, A. A. (1991). Research methodology in nursing. Pretoria: Kagiso. 